\title{
MISALIGNMENT AND LAG TIME OF WIND AND WAVE OCCURRENCE BASED ON 10 YEARS MEASUREMENTS IN THE NORTH SEA NEAR THE GERMAN COAST
}

\author{
$\underline{\text { Arndt Hildebrandt, Leibniz Universität Hannover, hildebrandt@lufi.uni-hannover.de }}$ \\ Remo Cossu, The University of Queensland, r.cossu@uq.edu.au
}

\begin{abstract}
MOTIVATION \& BACKGROUND
There are several intentions to analyze the correlation of wind and wave data, especially in the North Sea. Fatigue damage is intensified by wind and wave loads acting from different directions, due to the misaligned aerodynamic damping of the rotor regarding the wave loads from lateral directions. Furthermore, construction time and costs are mainly driven by the operational times of the working vessels, which strongly depend on the wind and wave occurrence and correlation.

Turbulent wind can rapidly change its direction and intensity, while the inert water waves react slowly in relation to the wind profile. Tuerk (2008) investigates the impact of wind and turbulence on offshore wind turbines by analyzing data of four years. The study shows that the wave height is increasing with higher wind speeds but when the wind speed drops the reaction of the waves is postponed. The dependence of the wave height on the wind speed is varying because of the atmospheric stability and different wind directions. Fischer et al. (2011) estimated absolute values of misalignment between wind and waves located in the Dutch North Sea. The study presents decreasing misalignment for increasing wind speeds, ranging up to 90 degrees for wind speeds below $12 \mathrm{~m} / \mathrm{s}$ and up to 30 degrees for wind speeds above $20 \mathrm{~m} / \mathrm{s}$. Bredmose et al. (2013) present a method of offshore wind and wave simulation by using metocean data. The study describes characteristics of the wind and wave climate for the North and Baltic Sea as well as the directional distribution of wind and waves. Güner et al. (2013) cover the development of a statistical wave model for the Karaburun coastal zone located at the southwest coast of the Black Sea with the help of wind and wave measurements and showed that the height of the waves is directly correlating with the duration of the wind for the last four hours.
\end{abstract}

\section{METHOD \& OBJECTIVES}

A database of 10 years recorded wind speed and direction (10min average at $33 \mathrm{~m}$ above LAT), significant wave height and direction (from $30 \mathrm{~min}$ records) was created from FINO 1 measurements located in the German Bight of the North Sea. In addition to the analysis of the wind wave characteristics of the whole 10 years, 83 storms with wind speeds of $20-36 \mathrm{~m} / \mathrm{s}$ and durations greater 20 hours were identified. Figure 1 shows the identified storms arranged on the abscissa by decreasing mean wind direction of the whole storm duration. The top ordinate shows the frequency of occurrence of the wind directions for each storm by the colorbar. The directional frequencies for each storm sum up to $100 \%$ and each vertical data set shows the distribution of wind directions in comparison to the simultaneous wave directions in the middle plot. The undermost plot shows the frequency of the misalignment of wind and wave directions for each storm, which tends to increase with shifting mean wind directions towards SSW (200 degrees).

Based on further details and comparisons this paper will present different approaches to extract characteristics and causes for varying misalignments of wind and wave incidents close to the German coast. Furthermore, the variation and characteristics of the time lag (up to $5 \mathrm{~h}$ ) of the waves to react to changing winds will be presented.
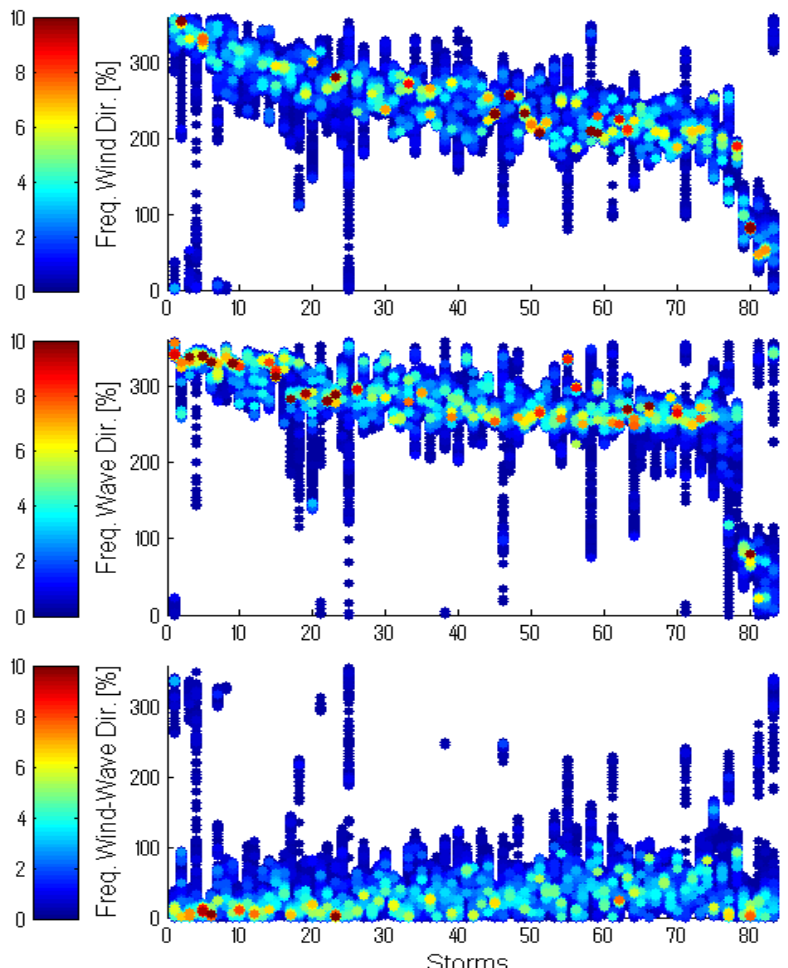

Figure 1 - Storms arranged by decreasing mean wind direction versus directional frequency of wind (top), wave (mid) and the misalignment of wind and waves (bottom).

\section{REFERENCES}

Bredmose, Larsen, Matha, Rettenmeier, Marino, Saettran (2012): Collation of offshore wind wave dynamics, DTU

Güner, Yüksel, Cevik (2013): Estimation of wave parameters based on nearshore wind-wave correlations, Ocean Engineering, vol. 63, pp. 52-62

Fischer, Rainey, Bossanyi, Kühn (2011): Study on Control Concepts suitable for Mitigation of Loads from Misaligned Wind and Waves on OWT supported on Monopiles, Wind Eng., Vol. 35, No. 5, pp. 561-574 Tuerk (2008): Ermittlung design relevanter Belastungsparameter für Offshore Windkraftanlagen, Dissertation, Universität Köln 